\title{
The Relativity of Theory by Moti Mizrahi: Reply by the Author
}

Moti Mizrahi

Studies in History and Philosophy of Science

I'm grateful to Aleta Quinn and Studies in History and Philosophy of Science for hosting this book forum. I'm also grateful to Margaret Greta Turnbull and Joseph Martin for their commentaries. In what follows, I address their comments as I understand them.

Turnbull is concerned that I'm being unfair to antirealists. In Chapter 1, I use the example of COVID-19, and measures taken to curtail the spread of the novel coronavirus SARS-CoV-2, such as social distancing, to illustrate the significance of the scientific realism/antirealism debate. If one is agnostic about the existence of unobservables like viruses, as antirealists are, then it's difficult to see how one could be motivated to practice social distancing and follow other public policies designed to reduce the spread of SARS-CoV-2. Turnbull agrees that "it would seem a bit odd to engage in social distancing practices if one actively believed that there is nothing in the universe which remotely resembles anything like a pathogen." However, Turnbull suggests that antirealists are not committed to agnosticism about pathogens because some bacteria are observable. As Turnbull puts it, "we can observe some bacteria directly through a simple (as opposed to, for example, an electron) microscope." To me, Turnbull's use of the term "direct" when talking about observation with the aid of instruments, such as microscopes, is confusing because antirealists are generally keen on distinguishing between direct observation and mere detection. The former can only be done without the aid of instruments. As van Fraassen (2001, p. 154) puts it, "We can detect the presence of things and the occurrence of events by means of instruments. But in my book that does not generally count as observation. Observation is perception, and perception is something that is possible for us without instruments." A microscope is an instrument, and so "observing" bacteria through a microscope doesn't count as direct observation in the constructive empiricist's book. Besides, viruses are too small to be "observed" (or detected) by means of optical microscopes. To "observe" (or detect) viruses like SARS-CoV-2, an electron microscope is needed.

Turnbull goes on to suggest that antirealists could be motivated to practice social distancing without being committed to any theory about unobservable viruses. As Turnbull puts it, "To take COVID-19 social distancing practices seriously, it seems to me, you need merely hold some theory of disease remotely resembling 'diseases are sometimes passed between individuals who are in physical proximity'." The problem with such a vague theory of disease is that it must be silent on important questions of public health, such as how much distance to put between oneself and others, what kind of cloth to use for masks, whether to double-mask, and so on. Such questions get their answers directly from our understanding of the nature of viruses and how they spread. Consequently, the point that the COVID-19 example was meant to illustrate still stands: whether one believes or is agnostic about the relevant science (e.g., the science about SARS-CoV-2 and COVID-19) would have some effect on one's decisions and any public policies one would be willing to endorse (e.g., social distancing).

In that respect, it's important to note that antirealists typically remain agnostic about, rather than deny the existence of, unobservables. Turnbull is concerned that my "language seems to imply that the antirealist actively denies that there exist unobservable entities that transfer disease between individuals." They could do both. As van Fraassen (2001, p. 151) says, "if it is 
unobservable then it is possible to be agnostic about its reality, even possible to say that it does not exist" (emphasis added). Both suspension of belief (agnosticism) and disbelief, however, would be rather poor motivators for action. For example, I have no belief or disbelief in aliens. For all I know, aliens may or may not exist, and I have no inclination either way. In that case, it would be very odd indeed if I were to behave as if aliens exist. Suppose that I were to take extra measures to always be with others, and never alone, so as not to get abducted by aliens. Such behavior would be very strange, given that I'm agnostic about the existence of aliens. Similarly, physically distancing oneself from others, wearing masks when around other people, and taking other measures to reduce the spread of SARS-CoV-2 and to protect oneself from COVID-19 would be very strange behaviors for someone who is agnostic about viruses like SARS-CoV-2 that cause infectious diseases like COVID-19.

Finally, Turnbull suggests that antirealists can be realists about disease transference but agnostic about the nature of such transference. As Turnbull puts it, "the antirealist is not bound by her antirealism to hold the view that disease transference does not occur when individuals are in physical proximity. She need merely suspend judgment about the nature of that disease transference. Presumably it is observable to her that she has contracted an illness some days after observing a person in close physical proximity to her coughing." First, if antirealists were to reason as Turnbull suggests, but without the theoretical background of virology, they would seem to be committing the post hoc fallacy. The mere occurrence of one event following another event doesn't mean that the two events are causally connected, unless there is an understanding of the causal mechanisms at work. Of course, antirealists are agnostic about the causal mechanisms at work, namely, viruses, so such a causal inference is not available to them.

More importantly, I don't think that disease transference would count as observable in the antirealist's book. Sickness, or rather some physical symptoms of sickness, such as vomiting and diarrhea, are observable. But the transfer of disease from one person to another would not count as directly observable in the antirealist's book. And "if it is unobservable then it is possible to be agnostic about its reality, even possible to say that it does not exist" (van Fraassen 2001, p. 151). Consequently, I still think that the stakes are high when it comes to the scientific realism/antirealism debate. Suspension of belief (agnosticism) in the theoretical posits of science cannot seem to motivate people to act in accordance with the recommendations of science. In fact, it wouldn't be unreasonable to suggest that many of the people who think that COVID-19 is a "hoax" are those who refuse to practice social distancing and wear masks in public.

Unlike Turnbull, Martin approaches my book "as a historian," "not as a philosopher." He takes issue with what I say about the role of historical evidence in the scientific realism/antirealism debate. Martin provides an argument whose conclusion is that positions "in the realism/antirealism issue should account for known relevant historical evidence." But that is precisely the problem. Both realist and antirealist positions account for the relevant historical evidence. Antirealists claim that some historical case study cannot be accommodated by scientific realism, and realists reply that it can be. For example, Laudan (1981, p. 33) argues that realism cannot accommodate the case of "the phlogiston theory of chemistry," and Ladyman $(2011$, p. 87) argues that "the case of phlogiston theory is shown to be readily accommodated by ontic structural realism." If competing theories accommodate or account for the same evidence, then that evidence is not decisive, i.e., it doesn't favor one theory over the other. 
Contrary to what Martin claims, then, I'm not suggesting that we should "disregard the [historical] data entirely!" Rather, my argument is that historical evidence is not decisive, i.e., it doesn't favor realism over antirealism (and vice versa), because both realist and antirealist positions account for the historical evidence. If realism and antirealism are epistemically indistinguishable, given that they are equally well supported by the historical evidence, then there are no positive historical reasons to believe one over the other. This is a version of the familiar underdetermination of theory by evidence argument but applied to historical evidence as it is used in the scientific realism/antirealism debate. Indeed, it has been a feature of the debate that, looking at the historical record of science, realists see success, whereas antirealists see failure. If realists can select historical facts and case studies from the history of science that support a realist position about science, whereas antirealists can select historical facts and case studies from the history of science that support an antirealist position about science, then historical facts and case histories do not favor one position over the other. This doesn't mean that historical evidence should be disregarded entirely. But it does mean that historical evidence is indeterminate between realist and antirealist positions about science.

If arguments from historical evidence are not decisive, then we need different kinds of arguments to move the scientific realism/antirealism debate forward. That is precisely what the arguments for Relative Realism aim to accomplish. The arguments for Relative Realism are not inductive arguments from historical case studies. Nor are they inferences to the best explanation. Rather, they are deductive arguments from the comparative nature of theory evaluation and the relative nature of the predictive success of scientific theories. As such, they are arguments that proceed from premises that both realists and antirealists could accept, and thus move the debate forward.

In his commentary, Martin says nothing about my other arguments concerning the use of historical evidence in the debate, specifically those about the kind of support case studies are supposed to give to philosophical theories about science. For case studies are "particular, detailed descriptions of scientific activity" (Currie 2015, p. 553), whereas realism and antirealism are general theories about the nature of science. So, "How much support [if any] does a single case study (or even a number of case studies) provide a general principle about the nature of science?" (Bishop and Trout 2002, S204). A particular, detailed description of scientific activity cannot provide valid deductive support for a general principle about the nature of science because a particular description doesn't entail a general principle. And a particular, detailed description of scientific activity cannot provide strong inductive support for a general principle about the nature of science because to generalize from a particular description is to commit the fallacy of hasty generalization. So, even if historical case studies should play an evidential role in the debate, it's not clear what kind of support they could provide to general theories about the nature of science, such as realism and antirealism. Reciting Lakatos' (1970) dictum is not enough. Those who want to secure an evidential role for historical case studies in the debate need to demonstrate precisely what sort of evidential support a historical case study can give to general theories about the nature of science.

Finally, Martin mentions that he has "some reservations about relative realism," although he doesn't articulate them. He also mentions in passing that "most realists would reject" the notion of comparative truth, but he doesn't say why. However, as I argue in the book, with textual evidence, realists would probably accept the notion of comparative truth because they accept that theory evaluation in science is comparative. For example, according to Musgrave 
(2017, p. 71), "As everybody also knows, science is empirical--scientists use observation and experiment to try to decide between the competing theories that they propose" (emphasis added). Now, comparative theory evaluation can only warrant comparative judgments about the competing theories that are being evaluated against each other. In other words, by its very nature, comparative theory evaluation allows us to say which theory among a set of competing theories is comparatively true, i.e., closer to the truth relative to its competitors, but it doesn't allow us to say which theory is absolutely or likely true.

\section{References}

Bishop, M.A. and J.D. Trout. (2002). 50 years of successful predictive modeling should be enough: lessons for philosophy of science. Philosophy of Science 69:S197-S208.

Currie, A. (2015). Philosophy of science and the curse of the case study. In C. Daly (Ed.), The Palgrave Handbook of Philosophical Methods (553-572). London: Palgrave MacMillan.

Ladyman, J. (2011). Structural realism versus standard scientific realism: the case of phlogiston and dephlogisticated air. Synthese 180:87-101.

Lakatos, I. (1970). History of science and its rational reconstructions. PSA: Proceedings of the Biennial Meeting of the Philosophy of Science Association 1970:91-136.

Laudan, L. (1981). A confutation of convergent realism. Philosophy of Science 48:19-49.

Mizrahi, M. (2020). The Relativity of Theory: Key Positions and Arguments in the Contemporary Scientific Realism/Antirealism Debate. Cham: Springer.

Musgrave, A. (2017). Strict empiricism versus explanation in science. In E. Agazzi (Ed.), Varieties of Scientific Realism: Objectivity and Truth in Science (71-94). Cham: Springer.

van Fraassen, B.C. (2001). Constructive empiricism now. Philosophical Studies 106:151-170. 